Azotobacter and Its Use in Agriculture

By L. I. Rubenchik. Translated from the Russian by Dr. A. Artman. Pp. vi +278 . (Jerusalem: Israel Program for Scientific Translations; London: Oldbourne Press, 1963.) $70 s$.

N ON-SYMBIOTIC nitrogen-fixing bacteria were first discovered in 1901 when Beijerinck isolated Azotobacter chroococcum from soil. Since then members of this genus have excited and interested microbiologists perhaps more than any other soil bacterium; the literature is very extensive and yet this monograph by Dr. L. I. Rubenchik is the first to be published on the subject. Dr. A. Artman's very readable translation of the Russian text means that it is now available to a much wider public. The title, Azotobacter and Its Use in Agriculture, is somewhat misleading because this is a general book about Azotobacter with chapters discussing, for example, morphology and life-cycles, physiology and biochemistry and ecological relationships in soils, rather than a specialist book on the use of Azotobacter in agriculture.

Dr. Rubenchik has summarized clearly and concisely the main conclusions from more than 979 papers, but reference to the original work is essential for detailed information. In abstracting the literature more emphasis is laid on Soviet work than that from other countries, and this is particularly valuable, as much of this information is not easily available in Britain, for example, and always has to be translated. A disadvantage of emphasis on early work is illustrated in the section on cultivation of Azotobacter. Here the media and methods described are out of date and very complicated; much simpler ones are now available. The section on the mechanism of nitrogen fixation summarizes the situation very well and is an unusual approach to the subject. Emphasis of some of the earlier theories which tend to be neglected and summaries of more modern Russian work should stimulate those interested in this topic. The chapter on use of Azotobacter in agriculture is good and most useful to anyone interested in this topic.

Because the value of this book lies in its enormous bibliography it is a pity that this should be so difficult to use. The literature is separated into Russian and other languages, not all references are in chronological or alphabetical order, some are not listed at all and the spelling of some names differs in the text and bibliography, although the publishers have often, but not always, put a footnote to this effect.

The general lay-out of the book is pleasing; the chapters are well subdivided, which means that particular topics can be found easily. This monograph will be very valuable to anyone interested in Azotobacter.

Margaret E. Brown

\section{Flora of West Tropical Africa}

All Territories in West Africa South of Latitude $18^{\circ} \mathrm{N}$. and to the West of Lake Chad, and Fernando Po. Vol. 2. By J. Hutchinson and J. M. Dalziel. Second edition edited by F. N. Hepper. Pp. xi +544 . (Published on behalf of the Governments of Nigeria, Ghana, Sierra Leone and Gambia by the Crown Agents for Oversea Governments and Administrations, 1963.) $80 s$.

$\mathrm{P}$ UBLICATION of Volume 2 (Dicotyledons-Metachlamydae) of the revised Flora of West Tropical Africa has been eagerly awaited by those interested in the West African flora. Publication of the original edition in 1931 stimulated considerable collection throughout the area and this has been reflected in the greatly increased number of species in the second cdition. This wealth of material has now made possible the critical re-examination of many species that were insufficiently known at the earlier date. The development of universities in West Africa, the expansion of national herbaria, and the increase in taxonomic work being earried out in the field have led to a number of families being revised by workers in West Africa itself, which is a welcome innovation.

Although, inevitably in such a work, certain sections are already out of date, the possibility of the field worker being able more closely to identify his specimens will lead to further increase in collection and knowledge of the West African flora. In particular, the inclusion in this volume of the complete family key to the Dicotyledons should prove of great interest to students and the increasing number of people who, while not being specialized taxonomists, take an interest in the local plants of their country.

It is only a pity that, in spite of soft covers, present-day costs of production have made a high selling price necessary. Publication of this volume should serve as a further stimulus to collection in West Africa. Only the Monocotyledons remains to be dealt with, and the publication of the remaining section and the consequent completion of the revision is awaited with great eagerness.

\section{E. H. RoBerts}

Planetary, Lunar, and Solar Positions A.D. 2 to A.D. 1649 at Five-day and Ten-day Intervals

By Bryant Zuckerman. (Memoirs of the American Philosophical Society, Vol. 59.) Pp. vii +842 . (Philadelphia: American Philosophical Society, 1964.) 7.50 dollars.

7 HIS volume, together with an earlier one which appeared as Volume 56 of tho Memoirs of the American Philosophical Society, provides celestial longitudes and latitudes with respect to the mean equinox of date of the Sun, Moon and five naked-eye planets covering the whole period from 601 B.C. to A.D. 1649, with an estimated error of $0.2^{\circ}$ for the Moon and a few hundredths of a degree for the other objects. The former volume was intended to provide for the coverage of Babylonian astronomy, and the present volume covers the periods of Roman astronomy, the whole development of Islamic astronomy from the ninth to the fifteenth centuries, the contemporary Hindu and Byzantine astronomy, and extends far enough to cover the work of Tycho Brahe and Kepler. Positions are given at five-day intervals for Mercury, Venus and the Moon, and ten-day intervals for the Sun, Mars, Jupiter and Saturn. The present volume was calculated on an IBM 7094 computer, taking in all $12 \mathrm{~h}$ of computer time, a truly remarkable illustration of the power of modern astronomical computing to contribute to the data for interpreting ancient astronomical records. Both volumes are splendid examples of the art of printing from mechanically printed tabular material and of the arrangement of very large quantities of tabular material.

R. H. Garstang

Appendix to the Second Edition of an Index of Mineral Species and Varieties Arranged Chemically

By Dr. Max H. Hey. Pp. xiii + 135. (London: British Museum (Natural History), 1963.) 20s.

THE second edition of Dr. Hey's invaluable Index of Mineral Species was published in 1955 (see review in Nature $, 178,114 ; 1956)$ and this edition was reprinted in 1962 , with the errata of the previous printing corrected. The Appendix to the second edition includes all new material that had come to the notice of the author up to December 1962. It also incorporates into the text, with this new material, all the addenda that appear on pp. $725-728$ in the second edition. In addition, it lists the errata for both the original printing and the reprint of this edition. It is thus equally valuable to possessors of either printing of the second edition. The decision to issue a moderately priced Appendix, rather than a completely new and inevitably expensive revised edition which would have entailed the expenditure of much time and labour, will no doubt be welcomed by the many users of this work of reference, who can now bring themselves up to date at minimal cost. 